\title{
Subacromial impingement syndrome: a survey of Italian physiotherapists and orthopaedics on diagnostic strategies and management modalities
}

Fabrizio Brindisino ${ }^{1,2^{*}}$, Diego Ristori ${ }^{3} \mathbb{B}$, Mariangela Lorusso ${ }^{2} \mathbb{D}$, Simone Miele ${ }^{3} \mathbb{B}$, Leonardo Pellicciari ${ }^{4} \mathbb{D}$, Giacomo Rossettini ${ }^{3}$ (D) Francesca Bonetti ${ }^{2}$ D, John Duane Heick ${ }^{5}$ and Marco Testa ${ }^{3}$ (D)

\begin{abstract}
Background and aim: The subacromial impingement syndrome (SIS) represents a common cause of disability in approximately $74 \%$ of patients with Shoulder Pain (SP). Even if contemporary research suggests that this mechanism is not (always) the dominant driver in SP, SIS is still a source of debate among scholars and clinicians. From a clinical point of view, evidence has suggested that clinicians can use both medical and physiotherapy approaches as effective methods to treat SIS.

This survey aims to investigate models of management of patients with SIS in a sample of Italian physiotherapist specialists (Orthopaedic Manipulative Physical Therapists, -OMPTs-) and orthopaedic surgeons.

Materials and methods: An online survey with 29-item questionnaire was administered to assess the knowledge of OMPTs and orthopaedic surgeons about: a) strategies of clinical examination; b) the role of imaging in the diagnostic process; c) the physiotherapy management; and d) the pharmacological and surgical management in patients with SIS.

Results: Six-hundred and twenty-nine respondents completed the survey (511 OMPTs (79.97\%) and 128 orthopaedic surgeons (20.03\%)). Ninety-two percent $(n=470)$ of the OMPTs and $80.5 \%(n=103)$ of orthopaedic surgeons stated that in patients with SIS, a combination of diagnostic tests produced better accuracy $(p=<0.001)$. Twenty point seven $\%$ of OMPTs $(n=106)$ and $4.7 \%$ of orthopaedic surgeon $(n=6)$ stated that the Lift off was the most specific test $(p=<0.001)$. Four-hundred-and-twenty-four OMPTs (83\%) and 40 orthopaedic surgeons (31.3\%) answered that the gold standard for diagnosis of a patient with SIS are history and clinical examination $(p<0.001)$.

Conclusion: OMPTs and orthopaedic surgeons approach patients with SIS differently during both the assessment and the treatment. OMPTs appear to be appropriate in planning and managing clinical examination and therapeutic strategies to use with patients with SIS.
\end{abstract}

Keywords: Shoulder impingement syndrome, Orthopaedic manipulative physical therapists, Orthopaedic surgeons, Italian survey, Shoulder pain

\footnotetext{
* Correspondence: fabrindi@gmail.com

'Department of Medicine and Health Science "Vincenzo Tiberio", University

of Molise C/da Tappino c/o Cardarelli Hospital, 86100 Campobasso, Italy

${ }^{2}$ Department of Clinical Sciences and Translational Medicine, Tor Vergata

University of Rome, Rome, Italy

Full list of author information is available at the end of the article
}

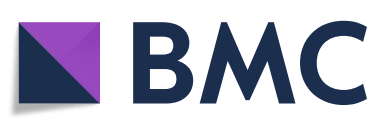

( The Author(s). 2020 Open Access This article is licensed under a Creative Commons Attribution 4.0 International License, which permits use, sharing, adaptation, distribution and reproduction in any medium or format, as long as you give appropriate credit to the original author(s) and the source, provide a link to the Creative Commons licence, and indicate if changes were made. The images or other third party material in this article are included in the article's Creative Commons licence, unless indicated otherwise in a credit line to the material. If material is not included in the article's Creative Commons licence and your intended use is not permitted by statutory regulation or exceeds the permitted use, you will need to obtain permission directly from the copyright holder. To view a copy of this licence, visit http://creativecommons.org/licenses/by/4.0/ The Creative Commons Public Domain Dedication waiver (http://creativecommons.org/publicdomain/zero/1.0/) applies to the data made available in this article, unless otherwise stated in a credit line to the data. 


\section{Background}

Shoulder pain (SP) is the third most common musculoskeletal disorder in the general population for which medical care is sought $[6,51]$. SP can significantly influence the patient's ability to work, as well as to perform daily life and recreational activities [68].

The prevalence of SP is estimated to range from 19 to $31 \%$ for monthly prevalence; from 5 to $47 \%$ for annual prevalence; and from 7 to $67 \%$ for lifetime prevalence [50]. The resolution of symptoms (e.g., pain, disability) may be gradual, thus resulting in a high relapse rate. For example, authors have noted that $25 \%$ of patients report a previous episode of SP and between 40 to $50 \%$ of patients report persistent pain at 12-month follow-up [42]. The annual incidence of SP varies according to the age of the patient: $0.9 \%$ between 31 and 35 years; $2.5 \%$ between 42 and 46 years; $1.1 \%$ between 56 and 60 years; and $1.6 \%$ between 70 and 74 years $[51,56]$.

The Cochrane revision of Hanchard, Lenza, Handoll and Takwoingi [36] identifies subacromial impingement syndrome (SIS) as a common cause of disability without joint stiffness, which occurs in approximately $74 \%$ of patients with SP. The pathoanatomical construct of SIS is debated at the international level among scholars and clinicians [7].

The most adopted classification of SIS has been based on localizing the soft tissue entrapment [23]. This classification differentiates internal causes - postero-superior impingement [72] and antero-superior impingement [30] -, from those occurring externally - "outlet impingement" [54]-, such as acromial spurs or uncinated acromion morphology causing extrinsic compression of the subacromial bursae and abrasion of the rotator cuff [28]. Subsequently, Lewis [45] has explained SIS as a consequence of an underlying loss of strength of the rotator cuff, which leads to an alteration of the centered position of the humerus onto the glenoid fossa [46]. Thus, it may be possible that patients presenting with a rotator cuff unable to perform its main function, are in the early stage of SIS $[45,49]$.

As a consequence of this international debate, SIS has been labelled as a clinical entity, rather than a diagnostic one, responsible for several functional and tissue alterations (e.g., rotator cuff lesions) [36, 41, 52]. Thus, impingement has been defined as an umbrella term for a range of signs and symptoms that are typically seen in patients with SP [37]. The current diagnostic process has been influenced by this concept and the importance of anamnesis and clinical examination in evaluating patients with SIS mirrors this approach. The evolution of knowledge through evidence has influenced clinicians' understanding in terms of signs and symptoms revealing SIS, as well as orthopaedic tests needed to assess the patient with SP. In fact, in addition to the controversial etiology and the multiplicity of structures and mechanisms that may be involved in SIS, there is also a lack of evidence to support the mechanical construct of physical tests for the diagnosis of SIS. Despite their common use in physical examination as provocative tools [47], their effectiveness in identifying (and isolating) the different structures responsible for the patient's symptom or replicating a single pathological mechanism has been questioned [7, 37]. Evidence has also influenced the use of imaging for the assessment of the patient with SIS - e.g., Ultrasound (US), Magnetic Resonance Imaging (MRI), Magnetic resonance Arthrography (MRA) - [7, 62].

From a clinical point of view, authors have suggested that clinicians can use both medical and physiotherapy approaches as effective methods to treat SIS. Several physiotherapy treatments for SIS are proposed in the literature, including electrotherapy (e.g., laser, US, heat, shock waves) and taping techniques, as well as manual therapy and therapeutic exercises [18, 20, 55, 73]. Medical treatments for SIS range from pharmaceutical treatments (e.g., Non-Steroidal Anti Inflammatory Drugs NSAID- and corticosteroids injections) to surgical approaches (e.g., arthroscopic subacromial decompression, open subacromial decompression, arthroscopic bursectomy, acromioplasty performed with radio frequency therapy, injections of platelet and leukocyte enriched gel) $[18,19,25,29,64]$.

Since there is a wide range of approaches for patients with SP related to SIS, some countries (e.g., United Kingdom, Germany, Netherlands) have conducted surveys aimed at investigating if specific clinicians' assessment and interventions for patients with SP follow evidence-based practice $[9,48,58,59,67]$.

Given the lack of data in Italy regarding how specific clinicians assess and treat patients with SIS, this survey aims to investigate models of management of patients with SIS by Italian physiotherapist specialists (Orthopaedic Manipulative Physical Therapists, --OMPTs-) and orthopaedic surgeons. These two categories have been chosen specifically because they include clinicians who routinely manage patients with SIS in Italy as well as in Europe [16]. A sub category of Italian physiotherapists -OMPTs-, specialized physiotherapists with musculoskeletal training were investigated because evidence supports that providers with advanced competencies are more likely to follow evidence-based practice in their clinical practice [8].

\section{Materials and methods Design}

A quantitative exploratory web-based cross-sectional survey was conducted that follows the CHERRIES guidelines [24] and STROBE guidelines [71]. The survey was administered between May and July 2019. Ethical 
approval was obtained from the Ethics Committee of Lecce (Italy) (Protocol number 33, approved on 06/06/ 2019). All the study-related procedures were performed according to the principles of the declaration of Helsinki [1].

\section{Participants and setting}

The target populations were Italian physical therapists specialized in musculoskeletal disorder rehabilitation (Orthopaedic Manipulative Physical Therapists -OMPTs-) and orthopaedic surgeons.

Participation was voluntary and no incentives were offered to participants in this survey. University Master courses are training courses required for specialization as OMPTs and are based upon the standards established by IFOMPT (International Federation of Orthopaedic Manipulative Physical Therapists) [5]. The sample of OMPTs was obtained from the databases of the following universities: a) Masters in Rehabilitation of Musculoskeletal Disorders (MRDM) at Genoa University $(n=$ 1300); b) Masters in Manual Therapy applied to Physiotherapy at Roma Tor Vergata University $(n=140)$; c) Masters in Manual Therapy and Musculoskeletal Rehabilitation at Padova University $(n=98)$; and d) Masters in Musculoskeletal Physiotherapy, Manual Therapy and Therapeutic Exercise at Bologna University $(n=32)$.

The sample of orthopaedic surgeons was identified from the databases of the 3 most representative Italian orthopaedic associations: a) SICSeG (Società Italiana Chirurgia di Spalla E Gomito) $(n=152)$; b) SIA (Società Italiana di Artroscopia) $(n=1470)$; c) and SIGASCOT (Società Italiana Ginocchio Artroscopia Sport Cartilagine e Tecnologie Ortopediche) $(n=1574)$ that encompasses surgeons specialized in shoulder and elbow surgery.

Clinicians were included if they: a) had a valid e-mail account, b) understood Italian; and c) were working as clinicians in Italy at the time of the survey. Previous surveys $[9,48,58,59,67]$ reported a response rate ranging from 3\% [67] to 21\% [59]. Pieters et al. [58] recruited a sample of 505 subjects, Bury and Littlewood [9] 191 subjects, Littlewood, Lowe and Moore [48] 110 respondents, Pribicevic, Pollard and Bonello [59] 112/1037 with a response rate of $21 \%$ and Struyf, de Hertogh, Gulinck and Nijs [67] 119/3877 had a response rate of 3\%. Taken all together, these previous surveys suggested that the potential response rate would range from 3.0 to $21.0 \%$.

\section{Questionnaire development}

The questions within the survey were derived from systematic reviews and meta-analysis to focus on patients with SIS and particularly on:

- clinical examination [22, 31, 36, 38, 43, 53];

- the role of imaging in the diagnostic process $[44,57,62]$;
- the physiotherapists' management $[15,33,34,65,70]$;

- and the surgical and pharmacological management of patients with SIS $[18,32,66]$.

The questions were critically evaluated for face validity [14] by 6 experts with extensive experience in shoulder diseases (two orthopaedic surgeons and four physical therapists -DR, FB, SM, ML-). These experts worked independently on the survey questions and agreed on the final edited questions by providing feedback on content accuracy, wording, question order and survey structure. When full agreement was achieved, a preliminary version of the survey, consisting of 29 questions ( 9 demographic questions and 20 technical questions), was piloted to 15 OMPTs ( $n=5$ North; $n=5$ Center; and $n=5$ South of Italy) and 15 orthopaedic surgeons $(=5$ North; $n=5$ Center; and $n=5$ South of Italy) aimed at increasing the content validity of the questions.

Moreover, the experts interviewed the sample of 15 OMPTs and orthopaedic surgeons to understand if the questions needed further clarity or if there were any confusing words that required further explanation. Based on their feedback no further edits were necessary. The average time needed to complete the survey was approximately $12.50 \mathrm{~min}$ which was advantageous as these clinicians are busy and are potentially unlikely to complete a survey that takes too much time [26]. The final version of the survey consisted of 29 questions (Appendix) that allowed for one answer per question.

In section (A), 9 multiple-choice questions were included to collect the following descriptive data: profession; experience in years; working environment; working field; working status; age; sex; geographic zone of work; and patients with a SIS diagnosis for more than 1 month were investigated.

Section (B) was composed of 20 multiple-choice questions focused on: special tests (5 questions); imaging techniques (4 questions); assessment of patients with SIS (4 questions); physical therapy (4 questions); pharmacological/surgical management of the patient with SIS (2 questions); and outcome measure collection (1 question).

\section{Data collection}

SurveyMonkey (Survey-Monkey, Palo Alto, California, www. surveymonkey.com) was used to collect data and was administered between April 28th, 2019 and June 25th, 2019. The time frame for data collection was considered adequate in accordance with previous surveys conducted on SIS where at the end of the 2 months there were no further requests to complete the survey [48].

Potential participants were initially invited to participate in the survey via email that outlined: a) the aim of the study; b) data handling (anonymity); c) the informed 
consent statement; and d) the invitation to complete the questionnaire.

Respondents provided consent to participate in the survey by clicking on the survey link. To encourage participation two email reminders were sent at both 4 and 6 weeks after the initial invite to participate in the survey.

When completing the survey, respondents were able to review and modify their responses using a back button before submitting their answers. After submission of the survey, respondents were unable to edit their answers. For data analysis, answers were downloaded and stored to a password protected and encrypted computer. Only the statistician (LP) accessed and analysed the data collected from the surveys. All data were de-identified (name and email address) to maintain confidentiality and data protection [14].

\section{Data analysis}

Descriptive statistics were created by Survey Monkey and downloaded into Excel 2016 (Microsoft Corp. Redmond, WA, USA). Descriptive statistics (mean, standard deviation) were used for continuous variables, while absolute frequencies and percentages were applied to dichotomous, nominal, and ordinal variables. These variables were grouped by demographical data to define the sample recruited. OMPTs and orthopaedic surgeons were separated. Chi-squared tests were completed using SPSS, version 24 (IBM Corp., Armonk, NY, USA) to investigate differences in the responses between the two categories.

\section{Results}

In total, 639 respondents completed the survey with 511 OMPTs (79.97\%) and 128 orthopaedic surgeons (20.03\%) finalizing the questionnaire to be used in data analysis.

The majority of respondents were male (OMPTs: $n=$ 332; 65.0\%; orthopaedic surgeons: $n=115 ; 89.8 \%)$. The most representative age for OMPTs was $<30$ years old $(n=281 ; 55.0 \%)$, while orthopaedic surgeons were between 30 and 40 ( $n=44 ; 34.4 \%)$. The majority of respondents worked in Northern Italy (OMPTs $n=316 ; 61.8 \%$; orthopaedic surgeons $n=66 ; 51.6 \%)$ and in the musculoskeletal field (OMPTs $n=460 ; 90.0 \%$; orthopaedic surgeons $n=128 ; 100 \%)$. Most OMPTs worked in private practice $(n=387 ; 75.7 \%)$ while most orthopaedic surgeons were employees in the National Health System $(n=82 ; 64.1 \%)$.

The majority of OMPTs had worked for less than 5 years $(n=227 ; 44 \%)$ in a private setting $(n=423 ; 82.8 \%)$ and normally see less than 5 patients with SIS per month $(n=250 ; 48.9 \%)$. On the other hand, the majority of orthopaedic surgeons had worked for more than 15 years $(n=61 ; 47.7 \%)$ in a hospital $(n=94 ; 73.4 \%)$ and normally see 5 to 10 patients with SIS per month $(n=$
39; 30.5\%). The respondents' demographics are described in Table 1.

Opinions on both diagnostic process (clinical examination, imaging screening), management of treatment (physiotherapy and medical treatment) and outcome measurement were collected. The detailed percentages for each respondent's answers for both OMPTs and orthopaedic surgeons, Odds Ratio values comparing the correct answer to the incorrect ones (based on the adherence of the answers to the available literature) and $p$ values are reported in Table 2 .

\section{Clinical examination}

Regarding the administration of special tests for patients with SIS, respectively $92 \%(n=470)$ of the OMPTs and $80.5 \%(n=103)$ of orthopaedic surgeons stated that in patients with SIS, a combination of diagnostic tests produced better accuracy (e.g., the ability to differentiate correctly between patient and healthy subjects) [3] ( $p<$ 0.001 between groups).

Regarding the specificity of diagnostic tests, most OMPTs answered that the Empty can test had the highest specificity $(n=159 ; 31.1 \%)$, and the Neer sign had the least specificity $(n=102 ; 20.0 \%)$. In the sample of orthopaedic surgeons, most answered that the Hawkins-Kennedy test has the highest specificity $(n=77 ; 60.2 \%)$ while the "Lift off test" had the lowest specificity $(n=6 ; 4.7 \%)$.

In regard to the difficulty to systematically apply diagnostic tests in patients with SIS, the majority of respondents in both samples (OMPTs: $n=336$; 65.8\%; orthoapedic surgeons: $n=60 ; 46.9 \%)$ stated that there are issues in interpreting the results of a study.

In terms of diagnosing patients with SIS, the majority of OMPTs stated that diagnosis should be reached by recording information from both the history and clinical examination $(n=424 ; 83.0 \%)$, while most orthopaedic surgeons responded with clinical examination and imaging $(n=75 ; 58.6 \%)$.

In regard to the question of what clinical tests are used for diagnosing SIS, the majority of OMPTs stated that diagnostic tests are able to correctly detect healthy subjects $(n=171$; 33.5\%). Most orthopaedic surgeons answered that clinical tests are able to diagnose those with SIS and can also identify those without SIS ( $n=62 ; 48.4 \%)$.

Detailed respondents' answers on clinical examination are described in Table 2 (Questions number 1-5).

\section{Imaging screening}

Regarding the most reliable techniques for detecting total or partial tears of the rotator cuff between USI, RMI, and RMA, the most common OMPT choice identified USI as the most favorable method in terms of cost-efficacy for investigating the total or partial tear 
Table 1 Demographical Data

\begin{tabular}{|c|c|c|c|}
\hline \multirow[t]{2}{*}{ Variables } & \multicolumn{3}{|l|}{ Samples } \\
\hline & Total $(\boldsymbol{n}=639)$ & OMPTs $(\boldsymbol{n}=511)$ & Orthopaedic surgeon $(\boldsymbol{n}=128)$ \\
\hline \multicolumn{4}{|l|}{ Gender } \\
\hline Male & $447(70.0 \%)$ & $332(65.0 \%)$ & $115(89.8 \%)$ \\
\hline Female & $192(30.0 \%)$ & $179(35.0 \%)$ & $13(10.2 \%)$ \\
\hline \multicolumn{4}{|l|}{ Age (Years) } \\
\hline$<30$ & $283(44.3 \%)$ & $281(55.0 \%)$ & $2(1,6 \%)$ \\
\hline$>50$ & $52(8.1 \%)$ & $10(2.0 \%)$ & $42(32.8 \%)$ \\
\hline $30-40$ & $232(36.3 \%)$ & $188(36.8 \%)$ & $44(34.4 \%)$ \\
\hline $40-50$ & $72(11.3 \%)$ & $32(6.3 \%)$ & $40(31.3 \%)$ \\
\hline \multicolumn{4}{|l|}{ Years of Clinical Practice } \\
\hline$<5$ & $251(39.3 \%)$ & 227 (44\%) & $24(18.8 \%)$ \\
\hline $5-10$ & $192(30.0 \%)$ & $172(33.7 \%)$ & $20(15.6 \%)$ \\
\hline $11-15$ & $96(15.0 \%)$ & $73(14.3 \%)$ & $23(18.0 \%)$ \\
\hline$>15$ & $100(15.6 \%)$ & $39(7.6 \%)$ & $61(47.7 \%)$ \\
\hline \multicolumn{4}{|l|}{ Workplace } \\
\hline Private practice & $456(71.4 \%)$ & $423(82.8 \%)$ & $33(25.8 \%)$ \\
\hline Hospital & $147(23.0 \%)$ & $53(10.4 \%)$ & $94(73.4 \%)$ \\
\hline Residential care (nursing home) & $36(5.6 \%)$ & $35(6.8 \%)$ & $1(0.8 \%)$ \\
\hline \multicolumn{4}{|l|}{ Field of Work } \\
\hline Musculoskeletal & $588(92.0 \%)$ & $460(90.0 \%)$ & $128(100 \%)$ \\
\hline Geriatric & $27(4.2 \%)$ & $27(5.3 \%)$ & $0(0.0 \%)$ \\
\hline Neurologic & $22(3.4 \%)$ & $22(4.3 \%)$ & $0(0.0 \%)$ \\
\hline Cardiac, respiratory, paediatric & $2(0.3 \%)$ & $2(0.4 \%)$ & $0(0.0 \%)$ \\
\hline \multicolumn{4}{|l|}{ Type of Working } \\
\hline Private Practice & $433(67.8 \%)$ & $387(75.7 \%)$ & $46(35.9 \%)$ \\
\hline Employee & $206(32.2 \%)$ & $124(24.3 \%)$ & $82(64.1 \%)$ \\
\hline \multicolumn{4}{|l|}{ Italian geographical zones } \\
\hline North & $382(59.8 \%)$ & $316(61.8 \%)$ & $66(51.6 \%)$ \\
\hline Centre & $166(26.0 \%)$ & $128(25.0 \%)$ & $38(29.7 \%)$ \\
\hline South & $91(14.2 \%)$ & $67(13.1 \%)$ & $24(18.8 \%)$ \\
\hline \multicolumn{4}{|l|}{ Patients with SIS Per Month } \\
\hline$<5$ & $272(42.6 \%)$ & $250(48.9 \%)$ & $22(17.2 \%)$ \\
\hline $5-10$ & $263(41.2 \%)$ & $224(43.8 \%)$ & 39 (30.5\%) \\
\hline $11-20$ & $61(9.5 \%)$ & $27(5.3 \%)$ & $34(26.6 \%)$ \\
\hline$>20$ & $43(6.7 \%)$ & 10 (2.0\%) & $33(25.8 \%)$ \\
\hline
\end{tabular}

Abbreviation: OMPTS Orthopaedic physical therapist, SIS Subacromial Impingement Syndrome

( $n=318 ; 62.2 \%)$, while most orthopaedic surgeons answered RMI $(n=82 ; 64.1 \%)$.

Regarding sensitivity of the imaging techniques for detecting full thickness tears of the rotator cuff, the majority of OMPTs $(n=240 ; 47.0 \%)$ and orthopaedic surgeons $(n=89$; 69.5\%) stated that RMA is more capable of detecting full thickness tear of the rotator cuff than USI or RMI.

Regarding the ability of the imaging techniques in diagnosing partial thickness rotator cuff tears, the majority of OMPTs $(n=187 ; 36.6 \%)$ and orthopaedic surgeons $(n=61 ; 47.7 \%)$ stated that USI and RMI have high specificity (defining the ability to detect patients with partial thickness rotator cuff tears).

Regarding diagnostic imaging and partial thickness tears specific to the Supraspinatus tendon, the majority of the OMPTs $(n=198 ; 38.7 \%)$ and orthopaedic surgeons $(n=72 ; 56.3 \%)$ stated that MRA is more specific compared to RMI. 


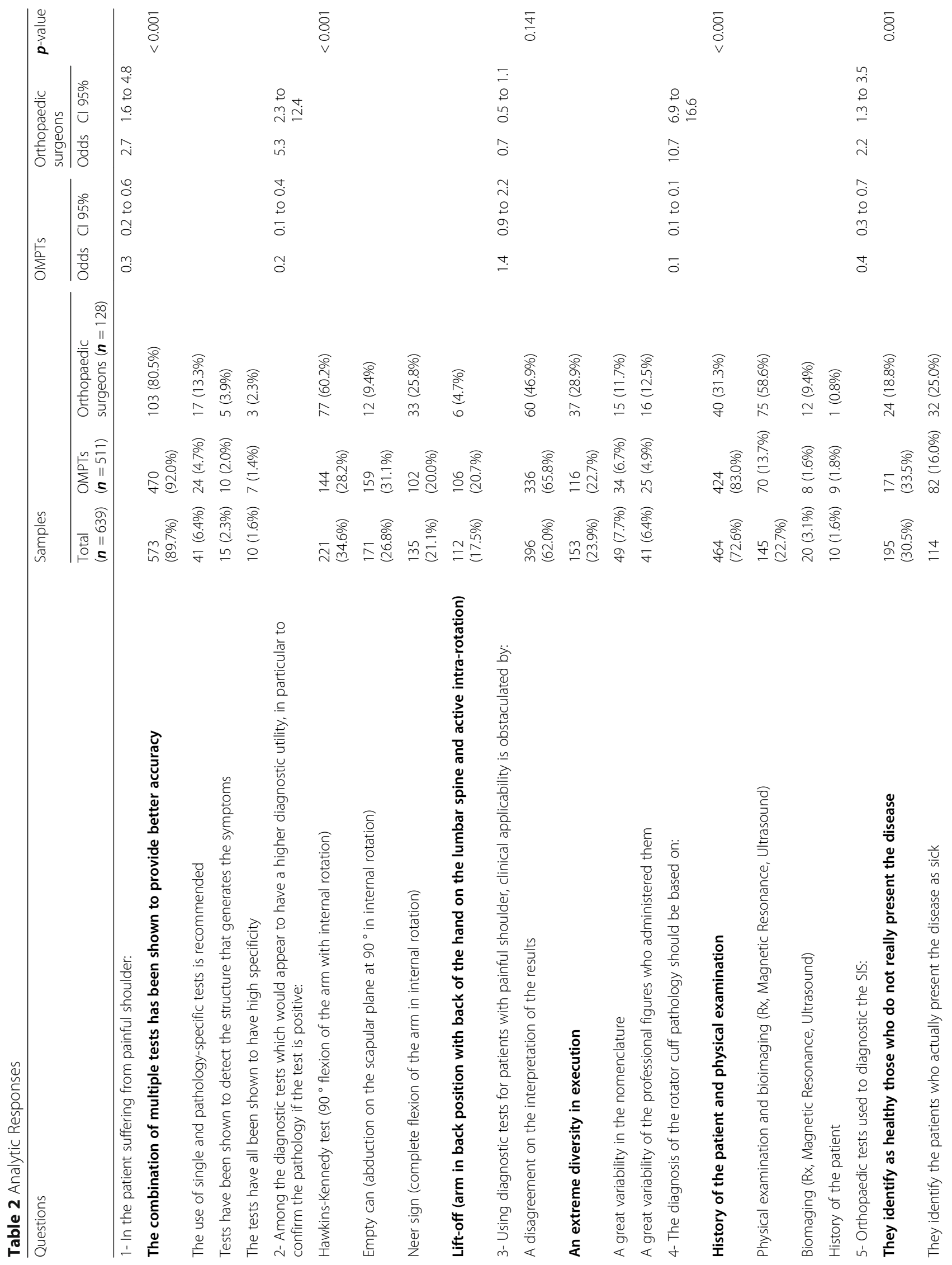




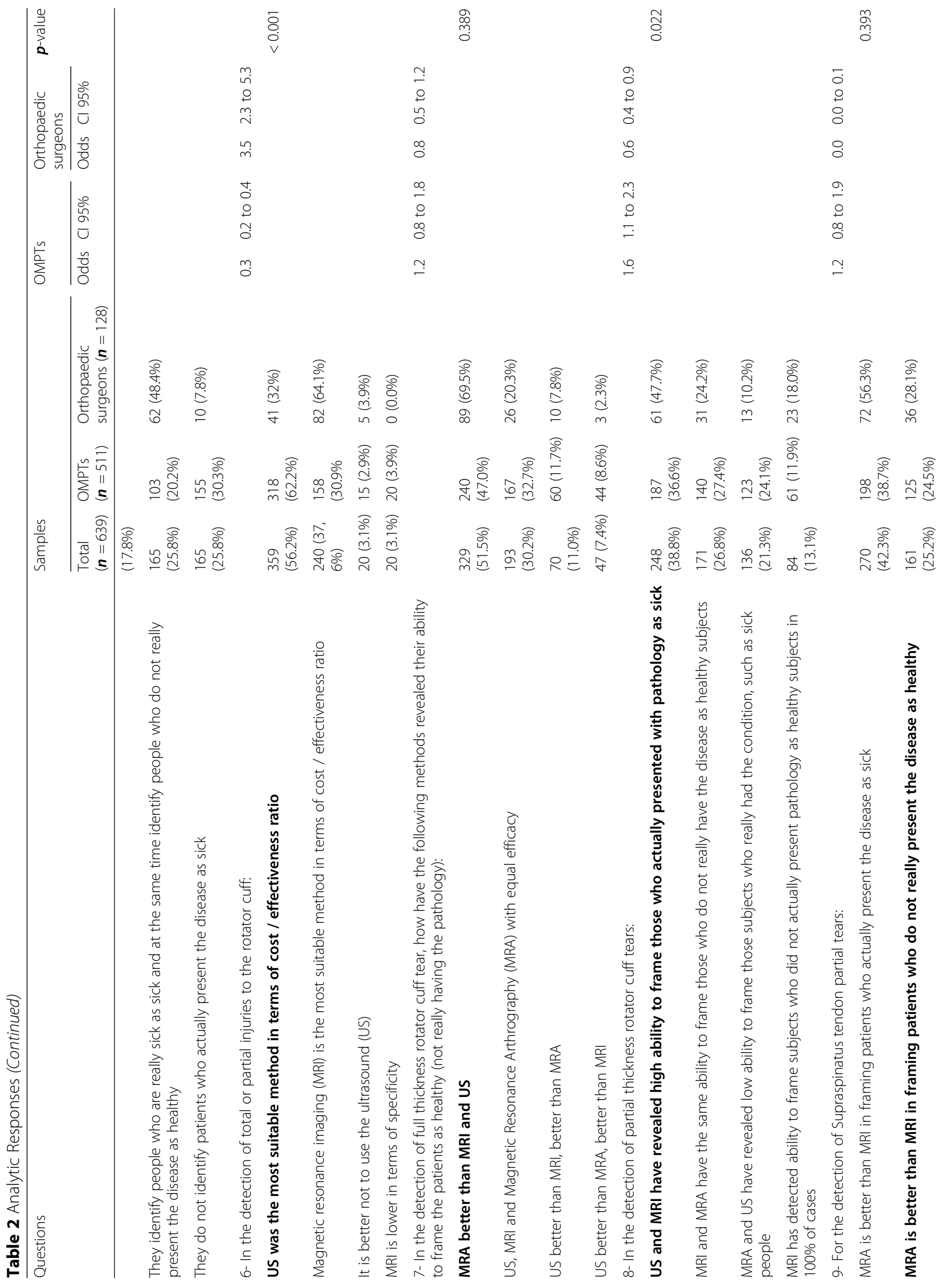




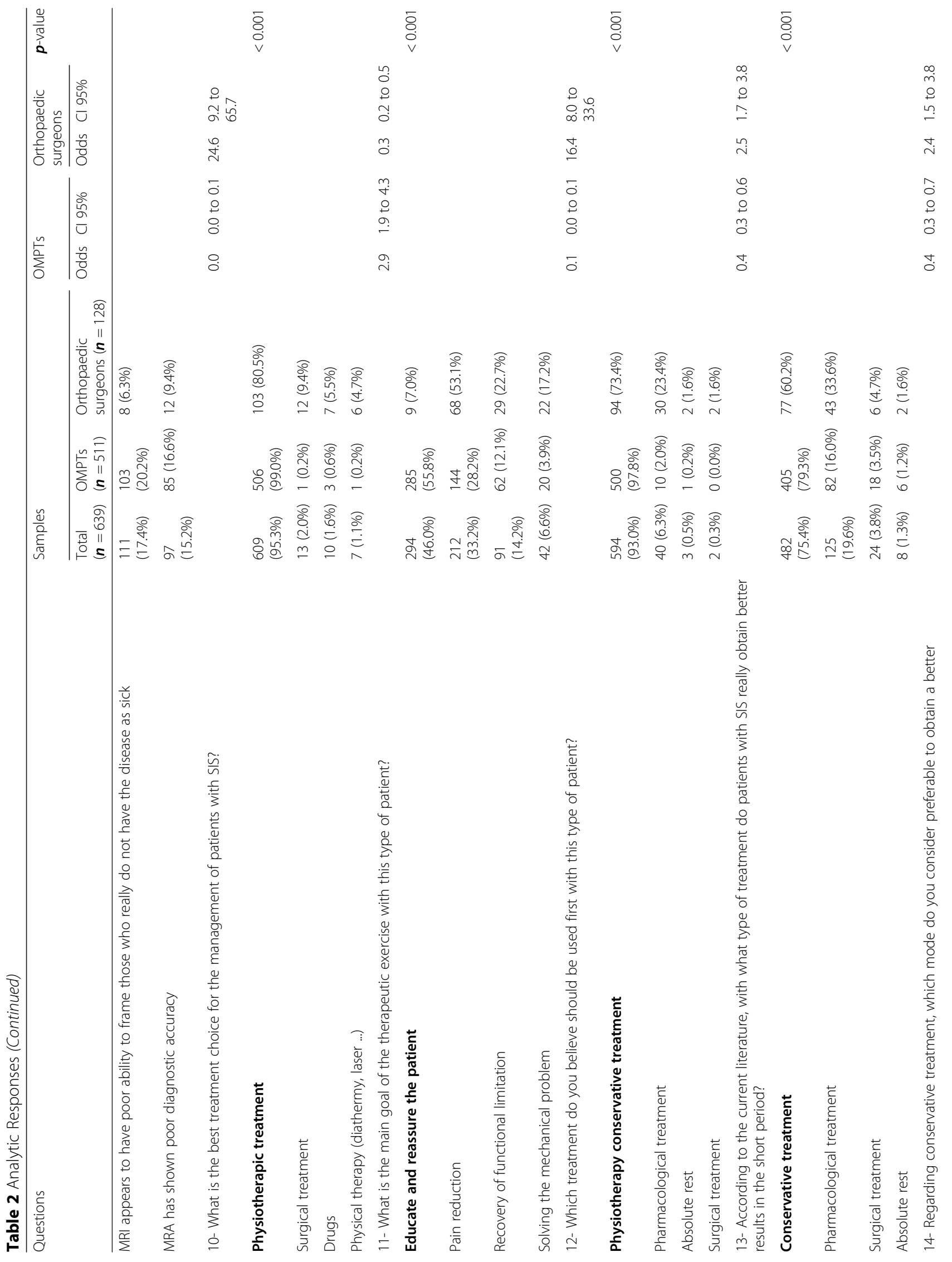




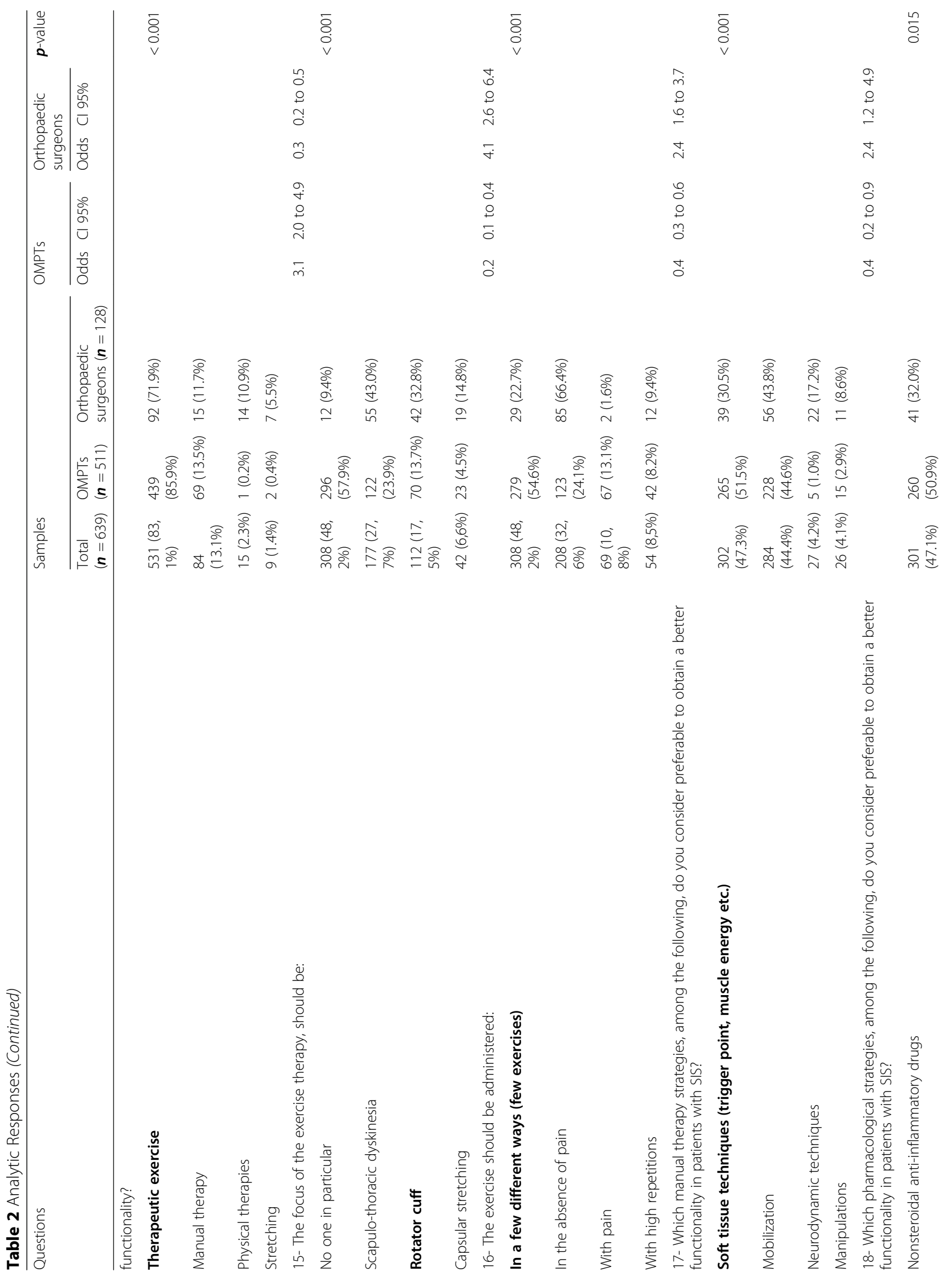




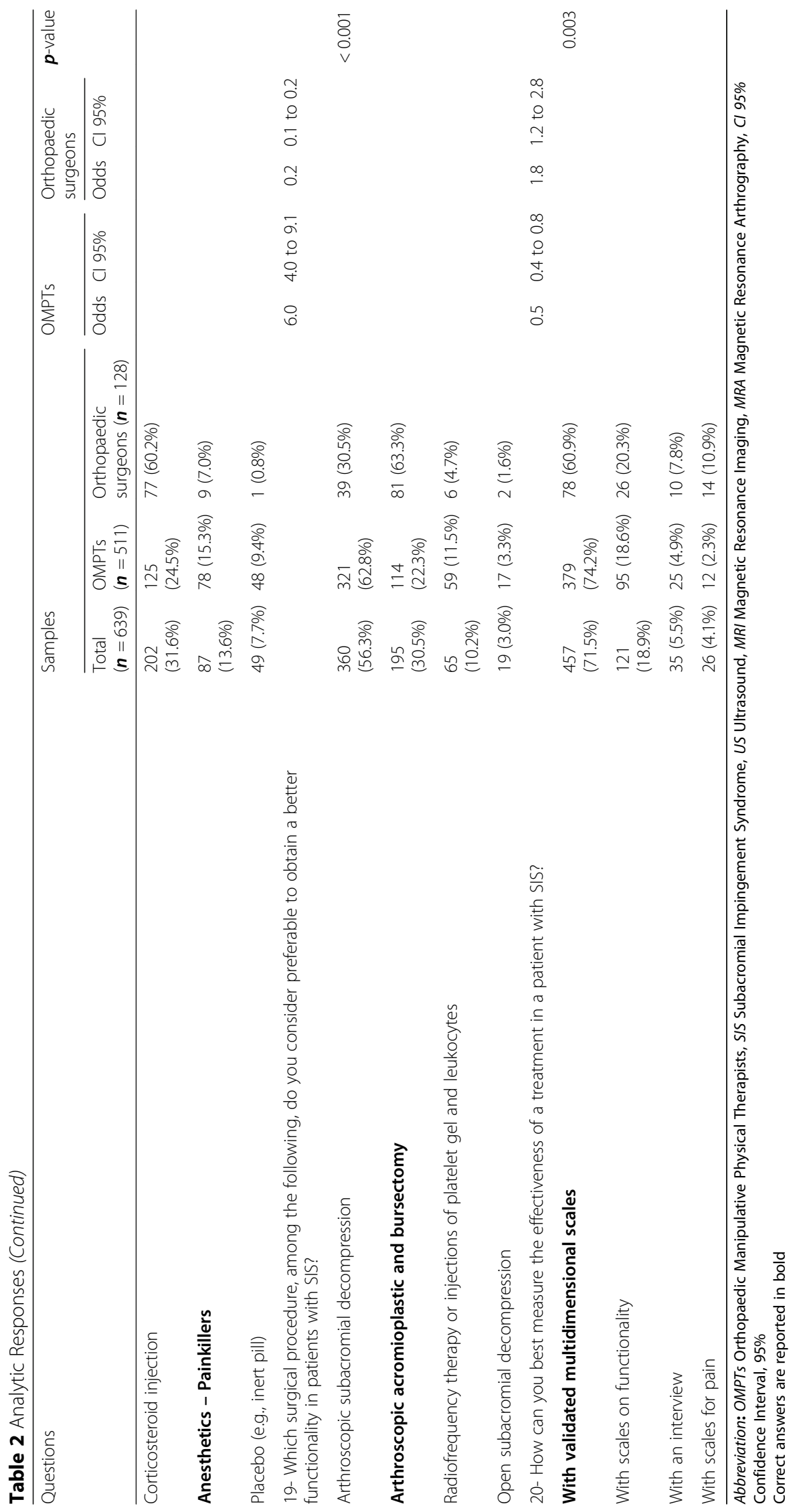


Detailed respondents' answers on imaging screening are shown in Table 2 (Questions number 6-9).

\section{Strategies of management}

Regarding strategies of management for patients with SIS, most respondents for both the samples answered physiotherapy treatment (OMPTs: $n=506$; $99.0 \%$; orthopaedic surgeons: $n=103$; $80.5 \%$ ).

In terms of what should be done at the first treatment for patients with SIS, most OMPTs $(n=500 ; 97.8 \%)$ and orthopaedic surgeons $(n=94 ; 73.4 \%)$ answered physiotherapy/conservative treatment.

In terms of what treatment has more short-term beneficial effect, most respondents answered conservative treatment (OMPTs: $n=405 ; 79.3 \%$; orthopaedic surgeons: $n=77 ; 60.2 \%)$.

Detailed respondents' answers on management strategies are described in Table 2 (Questions number 1013).

\section{Strategies of physiotherapy treatment}

Regarding which conservative strategy is more likely to recover function, for both samples most respondents answered therapeutic exercise (OMPTs: $n=439 ; 85.9 \%$; orthopaedic surgeons: $n=92 ; 71.9 \%$ ).

Regarding the main objective of therapeutic exercise in patients with SIS, the majority of OMPTs $(n=285$; $55.8 \%$ ) stated that education and reassurance of the patient should be the main objective, while the majority of orthopaedic surgeons $(n=68 ; 53.1 \%)$ identified pain reduction as the main goal.

Regarding the focus of therapeutic exercise, most OMPTs $(n=296 ; 57.9 \%)$ answered that exercise should not be targeted on a particular structure. Most orthopaedic surgeons $(n=55 ; 43.0 \%)$ answered that exercise should focus on scapular dyskinesis.

Regarding the administration of therapeutic exercise, most OMPTs $(n=279 ; 54.6 \%)$ answered that very few exercises should be administered in patients with SIS, while most orthopaedic surgeons $(n=85 ; 66.4 \%)$ responded that exercises should be pain-free.

Concerning the manual therapy modality that is more likely to promote functional recovery, most OMPTs $(n=265 ; 51.5 \%)$ answered techniques should target soft tissue; while most orthopaedic surgeons $(n=56 ; 43.8 \%)$ answered that mobilizations are more likely to promote functional recovery.

Detailed respondents' answers on physiotherapy strategies are shown in Table 2 (Questions number 14-17).

\section{Medical treatment}

Regarding which pharmacologic strategies are more likely to promote recovery of function, the majority of OMPTs $(n=260 ; 50.9 \%)$ felt that NSAIDs are more likely to promote recovery of function, while orthopaedic surgeons $(n=77 ; 60.2 \%)$ felt that corticosteroid injections were the answer.

In terms of the best surgical treatment for recovering function, OMPTs $(n=321 ; 62.8 \%)$ identified arthroscopic subacromial decompression, while orthopaedic surgeons $(n=81 ; 63.3 \%)$ chose arthroscopic bursectomy and acromioplasty.

Detailed respondents' answers on medical treatment are described in Table 2 (Questions number 18 and 19).

\section{Collection of outcome measures}

Regarding the most suitable outcome measures for patients with SIS, both samples of respondents agreed that PROs (patient reported outcomes) are the best outcome measures (OMPTs: $n=379 ; 74.2 \%$; orthopaedic surgeons: $n=78$; 60.9\%) ( $p=0.003)$.

Detailed respondents' answers on outcome measures collection are shown in Table 2 (Question number 20).

\section{Discussion}

To our knowledge, this is the first investigation regarding the adherence to the evidence in the assessment and treatment of patients with SIS performed among Italian clinicians. Our main finding indicates that OMPTs and orthopaedic surgeons choose different strategies in assessing and treating patients with SIS.

In accordance with evidence-based practice [16, 60], OMPTs attribute more value to the clinical examination and to the anamnesis in patients with SIS. Moreover, OMPTs were aware of the limitations of clinical tests and the valuable role that anamnesis and history provide in evaluating patients with SIS. These differences could be due to a higher predisposition in OMPTs to focus on function rather than a structural approach [39] compared to orthopaedic surgeons. This focus on function may have enhanced their use of the evidence, avoiding reliance on determining the structure that is causing the pain from SIS $[47,52]$.

In terms of imaging to identify partial or massive rotator cuff tears, our results (odds ratio and percentage) seem to be in favor of the orhopaedic surgeons, albeit by a non -statistically significant margin. However, in the current study, both categories of clinicians answered heterogeneously, highlighting the different findings of various studies on this topic [44]. One possible explanation could be that orthopaedic surgeons consider imaging as a key diagnostic factor due to its ability and competence in detecting structural failure, as well as for its utility in implementing the outcome in their practice $[11,22]$. OMPTs in the current study correctly recognized USI as the best tool (in terms of cost/benefit ratio) [17] in detecting partial and massive rotator cuff tears. Even if imaging is increasingly used for assessment of 
patients with SP, the correlation between structural failures and pain and its role in informing management remain unknown, leaving the interpretation of imaging findings as part of a wider construct of assessment in SIS [69].

From a therapeutic point of view, our results have revealed the different core competence of these two categories of clinicians. OMPTs possess knowledge in identifying the goals, priority of assessment tools and different rehabilitation modalities such as exercise or manual therapy. To date, therapeutic exercise appears to be the best conservative treatment in the management of SIS in terms of reduction of pain and improvement of function [35]. Still, there is no agreement in the literature about the parameters of the exercise such as number of repetitions, optimal load, typology of contraction or modality (e.g. supervised or not) [2]. Both OMPTs and orthopaedic surgeons identified exercise as the best conservative strategy. Furthermore, orthopaedic surgeons correctly identified the right purpose of exercises used in rehabilitation. Orthopaedic surgeons (68\%) were more competent than OMPTs $(22 \%)$ in detecting the best surgical approaches when needed. Unexpectedly OMPTs were aware of the most effective pharmacological treatments (in terms of anaesthetics and painkillers) [18] compared to orthopaedic surgeons (15\% vs $7 \%)$. Both OMPTs and orthopaedic surgeons indicated the use of NSAID or corticosteroids as high (respectively $\sim 75 \%$ and $\sim 92 \%$ ). This finding is consistent with the fact that NSAID and corticosteroids are the most studied drugs in the literature for patients with SIS [66]. It also suggests that both OMPTs and orthopaedic surgeons consider inflammation as the main source of the pain in patients with SIS $[18,73]$. This approach is limited to the biomedical model, not considering the biopsycosocial nature of the patient's symptoms of pain such as fear, self-efficacy and expectations [10, 13, 21, 49, 63].

The interpretation of data regarding PROs suggests that the concept of multidimensionality behind the patient's pain and health in general is not yet understood. Even if OMPTs are more inclined than orthopedic surgeons ( $74 \%$ vs $61 \%$ ) to use validated multidimensional scales, there is no statistically significant difference in relation to the choice of what instrument is used.

An interesting element emerges from the results of questions regarding the choices of therapeutic strategies for the patient. There is strong evidence suggesting that physiotherapy treatment is the best conservative strategy initially and for short-term effects $[4,12,65]$. OMPTs from the current study were more aware than orthopaedic surgeons about this, with a statistically significant difference in all three questions dedicated to this topic. Indeed, between 23 and 33\% of orthopaedic surgeons consider pharmacological treatment as the first and the most effective therapeutic intervention to advise patients with SIS for short-term relief of pain. As a possible source of explanation Italian OMPTs were trained by their University to apply conservative strategies for the management of the patients' complaints without using drugs or prescripting images (e.g., US, MRI, MRA) [27]. Contrarily, orthopaedic surgeons were educated to use drugs and to perform surgery during their University training, thus limiting their knowledge about physiotherapy and rehabilitation [40]. The results from the current study agree with other surveys on rotator cuff disorders performed in different European countries such as Italy [8], United Kingdom [9], Belgium and Netherlands [58].

A simplistic understanding of this data may suggest that OMPTs are better than orthopaedic surgeons when it comes to counselling a patient on optimum management. However, it should be taken into account that the population of OMPTs chosen were specialists (professionals specialized in musculoskeletal disorders rehabilitation). In addition, there are some differences between OMPTs and orthopaedic surgeons in terms of age (under 40 age: OMPTs 85\%; orthopaedics surgeons $35 \%$ ), experience (over 10 years OMPTs $77 \%$; orthopaedics surgeons $30 \%$ ) but also in setting (private practice: OMPTs $76 \%$; orthopaedics $36 \%$ ). These differences may have influenced the outcomes of the current study as not all OMPTs work in a direct access environment and are specialized in musculoskeletal disorders rehabilitation even if these OMPTs have less experience than the orthopaedic surgeons in the current study.

\section{Limits}

Limitations in every study exist and attempts are made to clear up as many as possible a priori in designing a study. Limits with submitting a survey are common as one does not know who will respond and how the questions will be interpreted by the respondent.

The first limitation within the current study is that there is not homogeneity of the two samples chosen for the survey which effects the generalization of the results. Thus, the results of this survey are specific to those who have responded to the survey at that point in time and the interpretation of the respondent answers may not be entirely accurate.

Sample characteristics could be the second limitation of this survey. Five-hundred-and-eleven OMPTs participated in our study from an overall Italian OMPTs population of 1570. In the current study, the authors chose to use OMPTs specialized in musculoskeletal management and not all physiotherapists in Italy are specialized in this area. Our sample represents $31 \%$ of Italian OMPTs which could be debated as being representative of all physiotherapists in Italy. It would have been ideal to have more but in conducting a survey it is hard to 
determine how many will respond. Regarding the number of males and young people in this sample, actually we think that this could be representative of the OMPT population in Italy. In fact most OMPTs in Italy are under 35 years $(82 \%)$ and are male $(70 \%)$ according to a previous survey on Italian OMPTs [61].

It also would have been ideal to have had the same number of orthopaedic surgeons answering the survey as physiotherapists but this was not the case. The sample of orthopaedic surgeons was not representative as it is equivalent to $4 \%$ of the overall population (128 out of 3196 of orthopaedic surgeons registered in the association responded to the survey). Future studies should attempt to have comparable sizes of both groups and homogeneous samples to compare and contrast the two groups and their responses. Perhaps future studies could consider investigating competency and adherence to efficacy testing across both populations, as well as how both populations assess and treat other common causes of shoulder pain for patients that present to both clinical practices (for example shoulder instability and adhesive capsulitis). Furthermore, future studies should be conducted in extra European countries because all surveys present in the literature investigate European physiotherapist samples.

\section{Conclusions}

In summary, OMPTs and orthopaedic surgeons approached patients with SIS somewhat differently on the initial visit for assessment and treatment. In this survey, Italian OMPTs specialized in musculoskeletal rehabilitation appear to be appropriate in planning and managing clinical examination and therapeutic strategies to use with patients with SIS.

\section{Appendix}

The online survey

Section (A) - Demographic questions

\section{1- Occupation}

a) Orthopaedic surgeon

b) OMPT

2- Gender
a) Male
b) Female

3- Age (Years)

a) $<30$ b) $31-40$

c) $41-50$

d) $>50$

\section{4- Years of clinical practice}
a) $<5$
b) $5-10$
c) $11-15$
d) $>15$

\section{5- Workplace}
a) Hospital
b) Residential care (nursing home)
c) Private practice

\section{6- Field of work}
a) geriatric
b) neurologic
c) musculoskeletal
d) cardiologic, respiratory, pediatric

\section{7- Type of work}

a) employee

b) private practice

\section{8- Italian geographical Zones}
a) North of Italy
b) Center of Italy
c) South of Italy

\section{9- Patients with SIS Per Month}
a) $<5$
b) $6-10$
c) $11-20$
d) $>20$

\section{Section (B) - Technical questions}

\section{0-In the patient suffering from painful shoulder:}

a) The combination of multiple tests has been shown to provide better accuracy; 
b) The use of single and pathology-specific tests is recommended;

c) Tests have been shown to detect the structure that generates the symptoms;

d) The tests have all been shown to have high specificity;

11-Among the diagnostic tests which would appear to have a higher diagnostic utility, in particular to confirm the pathology if the test is positive:

a) Hawkins-Kennedy test $\left(90^{\circ}\right.$ flexion of the arm with internal rotation)

b) Empty can (abduction on the scapular plane at $90^{\circ}$ in internal rotation)

c) Neer sign (complete flexion of the arm in internal rotation)

d) Lift-off (arm in back position with back of the hand on the lumbar spine and active intra-rotation)

12- Using diagnostic tests for patients with painful shoulder, clinical applicability is obstaculated by:

a) A disagreement on the interpretation of the results

b) An extreme diversity in execution

c) A great variability in the nomenclature

d) A great variability of the professional figures who administered them

\section{3- The diagnosis of the rotator cuff pathology} should be based on:

a) History of the patient and physical examination

b) Physical examination and bioimaging ( $\mathrm{Rx}$, Magnetic Resonance, Ultrasound)

c) Bioimaging ( $\mathrm{Rx}$, Magnetic Resonance, Ultrasound)

d) History of the patient

\section{4- Orthopaedic tests used to diagnosticate the SIS:}

a) They identify as healthy those who do not really present the disease

b) They identify the patients who actually present the disease as sick

c) They identify people who are really sick as sick and at the same time identify people who do not really present the disease as healthy

d) They do not identify patients who actually present the disease as sick

\section{5-In the detection of total or partial injuries to the} rotator cuff:

a) US was the most suitable method in terms of cost / effectiveness ratio

b) Magnetic resonance imaging (MRI) is the most suitable method in terms of cost / effectiveness ratio

c) It is better not to use ultrasound (US)

d) MRI is lower in terms of specificity

16-In the detection of full thickness rotator cuff tear, how have the following methods revealed their ability to frame the patients as healthy (not really having the pathology):

a) MRA (Magnetic Resonance Arthrography) better than MRI and US

b) US, MRI and MRA with equal efficacy

c) US better than MRI, better than MRA

d) US better than MRA, better than MRI

\section{7-In the detection of partial thickness rotator cuff} tears:

a) US and MRI have revealed high ability to frame those who actually presented with pathology as sick

b) MRI and MRA have the same ability to frame those who do not really have the disease as healthy subjects

c) MRA and US have revealed low ability to frame those subjects who really had the condition, such as sick people

d) MRI has detected ability to frame subjects who did not actually present pathology as healthy subjects in $100 \%$ of cases

\section{8- For the detection of Supraspinatus tendon} partial tears:

a) MRA is better than MRI in framing patients who actually present the disease as sick

b) MRA is better than MRI in framing patients who do not really present the disease as healthy

c) MRI appears to have poor ability to frame those who really do not have the disease as sick

d) MRA has shown poor diagnostic accuracy

19- What is the best treatment choice for the management of patients with SIS? 
a) Physiotherapy treatment

b) Surgical treatment

c) Drugs

d) Physical therapy (diathermy, laser ...)

20- What is the main goal of therapeutic exercise with this type of patients?

a) Educate and reassure the patient

b) Pain reduction

c) Recovery of functional limitation

d) Solving the mechanical problem

21- Which treatment do you believe should be used first with this type of patient?

a) Conservative physiotherapy treatment

b) Pharmacological treatment

c) Absolute rest

d) Surgical treatment

22-According to the current literature, with what type of treatment do patients with SIS really obtain better results in the short period?

a) Conservative treatment

b) Pharmacological treatment

c) Surgical treatment

d) Absolute rest

23-Regarding to conservative treatment, which mode do you consider preferable to obtain better functionality?

a) Therapeutic exercise

b) Manual therapy

c) Physical therapies

d) Stretching

24- The focus of the exercise therapy, should be:

a) Not one in particular

b) Scapulo-thoracic dyskinesia

c) Rotator cuff

d) Capsular stretching

\section{5- The exercise should be administered:}

a) In a few different ways (few exercises) b) In the absence of pain

c) With pain

d) With high repetitions

26- Which manual therapy strategies, among the following, do you consider preferable to obtain a better functionality in patients with SIS?

a) Soft tissue techniques (trigger point, muscle energy etc.)

b) Mobilization

c) Neurodynamic techniques

d) Manipulations (High Velocity Low Amplitude Thrust -HVLAT-)

27- Which pharmacological strategies, among the following, do you consider preferable to obtain a better functionality in patients with SIS?

a) Nonsteroidal anti-inflammatory drugs

b) Corticosteroid injection

c) Anesthetics - Painkillers

d) Placebo (e.g. inert pill)

28- Which surgical procedure, among the following, do you consider preferable to obtain a better functionality in patients with SIS?

a) Arthroscopic subacromial decompression

b) Arthroscopic acromioplastic and bursectomy

c) Radiofrequency therapy or injections of platelet gel and leukocytes

d) Open subacromial decompression

29- How can you best measure the effectiveness of a treatment in a patient with SIS?

a) With validated multidimensional scales

b) With scales on functionality

c) With an interview

d) With scales for pain

Acknowledgements

Not applicable.

Authors' contributions

$F B$, DR performed the conception and design of the study. FB, DR, SM and $M L$ performed the acquisition of data. LP performed analysis and interpretation of data. FB, DR, ML, SM, AND GR drafted the manuscript. GR, JDH, FBo and MT revised it critically for important intellectual content. All authors approved the final article version. FB and DR equally contributed to this work. 


\section{Funding}

LP was (partially) supported by founding of the Italian Ministry of Health (Ricerca corrente).

\section{Availability of data and materials}

The datasets used and/or analysed during the current study are available from the corresponding author on reasonable request.

\section{Ethics approval and consent to participate}

Ethical approval was obtained from the Ethics Committee of Lecce (Italy) (Protocol number 33, approved on 06/06/2019). All the study-related procedures were performed according to the principles of the declaration of Helsinki [1].

\section{Consent for publication}

Not applicable.

\section{Competing interests}

The authors declare that they have no competing interests.

\section{Author details}

'Department of Medicine and Health Science "Vincenzo Tiberio", University of Molise C/da Tappino c/o Cardarelli Hospital, 86100 Campobasso, Italy. ${ }^{2}$ Department of Clinical Sciences and Translational Medicine, Tor Vergata University of Rome, Rome, Italy. ${ }^{3}$ Department of Neuroscience, Rehabilitation, Ophtalmology, Genetics, Maternal and Child Health - University of Genova Campus of Savona, Savona, Italy. ${ }^{4}$ Neurorehabilitation Research Laboratory, IRCCS San Raffaele Pisana, Rome, Italy. ${ }^{5}$ Department of Physical Therapy and Athletic Training, Northern Arizona University Flagstaff, Flagstaff, AZ, USA.

Received: 4 March 2020 Accepted: 29 July 2020

Published online: 02 September 2020

\section{References}

1. 64th World Medical Association General Assembly, Declaration of Helsinki: ethical principles for medical research involving human subjects. 2013.

2. Abdulla SY, Southerst D, Cote P, Shearer HM, Sutton D, Randhawa K, et al. Is exercise effective for the management of subacromial impingement syndrome and other soft tissue injuries of the shoulder? A systematic review by the Ontario Protocol for Traffic Injury Management (OPTIMa) collaboration. Man Ther. 2015;20(5):646-56.

3. Baratloo A, Hosseini M, Negida A, El Ashal G. Part 1: Simple Definition and Calculation of Accuracy, Sensitivity and Specificity. Emerg (Tehran). 2015 Spring: 3(2):48-49. PMID: 26495380; PMCID: PMC4614595.

4. Beard DJ, Rees JI, Cook JA, Rombach I, Cooper C, Merritt N, Shirkey BA, Donovan JL, Gwilym S, Savulescu J, Moser J, Gray A, Jepson M, Tracey I, Judge A, Wartolowska K, Carr AJ, CSAW Study Group. Arthroscopic subacromial decompression for subacromial shoulder pain (CSAW): a multicentre, pragmatic, parallel group, placebo-controlled, three-group, randomised surgical trial. Lancet. 2018;27:329-38.

5. Beeton K, Langendoen J, Maffey L, Pool J, Hoke AP, Rivett D, et al. Educational Standards in orthopaedic manipulative therapy. 2008 [updated 2013; cited 20/01/2017]. http://www.ifOMPT.org/site/ ifOMPT/files/pdf/ XXIFOMPTEducStandardsIMDocMerged.pdf.

6. Bot SDM, van der Waal JM, Terwee CB, van der Windt D, Schellevis FG, Bouter LM, Dekker J. Incidence and prevalence of complaints of the neck and upper extremity in general practice. Ann Rheum Dis. 2005;64:118-23.

7. Braman JP, Zhao K, Lawrence RL, Harrison AK, Ludewig PM. Shoulder impingement revisited: evolution of diagnostic understanding in orthopedic surgery and physical therapy. Med Biol Eng Comput. 2014;52(3):211-9.

8. Brindisino F, Matteuzzi I, Mckreesh K, Bury J, Littlewood C. Rotator cuff disorders: a survey of current (2018) Italian physiotherapy practice. Physiother Pract Res. 2020;(41)1:11-22.

9. Bury J, Littlewood C. Rotator cuff disorders: a survey of current (2016) UK physiotherapy practice. Shoulder Elbow. 2018;0:1-10

10. Chester R, Jerosch-Herold C, Lewis J, Shepstone L. Psychological factors are associated with the outcome of physiotherapy for people with shoulder pain: a multicentre longitudinal cohort study. Br J Sports Med. 2018:52:26975.

11. Coghlan JA, Buchbinder R, Green S, Johnston RV, Bell SN. Surgery for rotator cuff disease. Cochrane Database Syst Rev. 2008;23(1):CD005619.
12. Consigliere $P$, Haddo $O$, Levy $O$, Sforza G. Subacromial impingement syndrome: management challenges. Orthop Res Rev. 2018;10:83-91.

13. Curry EJ, Matzkin E, Dong Y, Higgins LD, Katz JN, Jain NB. Structural characteristics are not associated with pain and function in rotator cuff tears: The ROW Cohort Study. Orthop J Sports Med. 2015;3(5): 2325967115584596.

14. de Leeuw D, Hox J, Dillman D. International Handbook of Survey Methodology (European Association of Methodology Series). 1st ed. New York: Taylor and Francis group; 2008.

15. Delgado-Gil JA, Prado-Robles E, Rodrigues-de-Souza DP, Cleland JA, Fernández-de-las-Peñas C, Alburquerque-Sendín F. Effects of mobilization with movement on pain and range of motion in patients with unilateral shoulder impingement syndrome: a randomized controlled trial. J Manip Physiol Ther. 2015;38(4):245-52.

16. Diercks R, Bron C, Dorrestijn O, Meskers C, Naber R, de Ruiter T, Willems J, Winters J, van der Woude J. Guideline for diagnosis and treatment of subacromial pain syndrome A multidisciplinary review by the Dutch Orthopaedic Association. Acta Orthop. 2014;85(4):314-22.

17. Dinnes J, Loveman E, Mclntyre L, Waugh N. The effectiveness of diagnostic tests for the assessment of shoulder pain due to soft tissue disorders: a systematic review. Health Technol Assess. 2003;7(29).

18. Dong W, Goost H, Lin XB, Burger C, Paul C, Wang ZL, Zhang TY, Jiang ZC, Welle K, Kabir K. Treatments for shoulder impingement syndrome a prisma systematic review and network meta-analysis. Med (United States). 2015; 94(10):1-17.

19. Donigan JA, Wolf B. Arthroscopic subacromial decompression: acromioplasty versus bursectomy alone-does it really matter? A systematic review. lowa Orthop J. 2011:31:21-126.

20. Dorrestijn O, Stevens M, Winters JC, van der Meer K, Diercks RL. Conservative or surgical treatment for subacromial impingement syndrome? A systematic review. J Shoulder Elb Surg. 2009;18(4):652-60.

21. Dunn WR, Khun JE, Sanders R, An Q, Baumgarten KM, Bishop YJ, Brophy RH, Carey JL, Holloway GB, et al. On behalf of the MOON shoulder group, symptoms of pain do not correlate with rotator cuff tear severity: a crosssectional study of 393 patients with a symptomatic atraumatic full-thickness rotator cuff tear. J Bone Joint Surg Am. 2014:96:793-800.

22. Edwards A, Chepeha J, Jones A, Sheps DM, Beaupré L. Can clinical assessment differentiate partial thickness rotator cuff tears from full thickness rotator cuff tears? A secondary analysis. Disabil Rehabil. 2020; 42(16):2351-8

23. Escamilla RF, Hooks T, Wilk KE. Optimal management of shoulder impingement syndrome. Open Access J Sports Med. 2014;28(5):13-24.

24. Eysenbach $\mathrm{G}$. Improving the quality of Web surveys: the Checklist for Reporting Results of Internet E-Surveys (CHERRIES). J Med Internet Res. 2004; 29(6):e34.

25. Faber E, Kuiper Jl, Burdorf A, Miedema HS, Verhaar JAN. Treatment of impingement syndrome: a systematic review of the effects on functional limitations and return to work. J Occup Rehabil. 2006;16(1):7-25.

26. Fan W, Yan Z. Factors affecting response rates of the web survey: a systematic review. Comput Human Behav. 2010;26(2):132-9.

27. Fisioterapisti, A.I.F.I., La Formazione "Core" Del Fisioterapista. 2018. AVAl LABLE FROM: https://aifi.net/wp-content/uploads/2018/07/ corecompetencecorecurriculum.pdf.

28. Garving C, Jakob S, Bauer I, Nadjar R, Brunner UH. Impingement syndrome of the shoulder. Dtsch Arztebl Int. 2017:114:765-76.

29. Gebremariam L, Hay E, Koes BW, Huisstede BM. Effectiveness of surgical and postsurgical interventions for the subacromial impingement syndrome: a systematic review. Arch Phys Med Rehabil. 2011;92(11):1900-13.

30. Gerber C, Sebesta A. Impingement of the deep surface of the subscapularis tendon and the reflection pulley on the anterosuperior glenoid rim: a preliminary report. J Shoulder Elb Surg. 2000;9(6):483-90.

31. Gismervik $S \varnothing$, Drogset JO, Granviken F, Rø M, Leivseth G. Physical examination tests of the shoulder: a systematic review and meta-analysis of diagnostic test performance. BMC Musculoskelet Disord. 2017;18(1):41.

32. Goldgrub R, Cote P, Sutton D, Wong JJ, Yu H, Randhawa K, et al. The effectiveness of multimodal care for the management of soft tissue injuries of the shoulder: a systematic review by the Ontario Protocol for Traffic Injury Management (OPTIMa) collaboration. J Manip Physiol Ther. 2016;39(2): 121-39.

33. Guimarães JF, Salvini TF, Siqueira AL Jr, Ribeiro IL, Camargo PR, Alburquerque-Sendín F. Immediate effects of mobilization with movement 
vs sham technique on range of motion, strength, and function in patients with shoulder impingement syndrome: randomized clinical trial. J Manip Physiol Ther. 2016;39(9):605-15.

34. Haik MN, Alburquerque-Sendín F, Camargo PR. Short-term effects of thoracic spine manipulation on shoulder impingement syndrome: a randomized controlled trial. Arch Phys Med Rehabil. 2017;98(8):1594-605.

35. Haik MN, Alburquerque-Sendin F, Moreira RF, Pires ED, Camargo PR. Effectiveness of physical therapy treatment of clearly defined subacromial pain: a systematic review of randomised controlled trials. Br J Sports Med. 2016;50(18):1124-34.

36. Hanchard NC, Lenza M, Handoll HH, Takwoingi Y. Physical tests for shoulder impingements and local lesions of bursa, tendon or labrum that may accompany impingement. Cochrane Database Syst Rev. 2013(4):CD007427.

37. Hegedus EJ, Cook C, Lewis J, Wright A, Park JY. Combining orthopedic special tests to improve diagnosis of shoulder pathology. Phys Ther Sport. 2015;16(2):87-92.

38. Hegedus EJ, Goode AP, Cook CE, Michener L, Myer CA, Myer DM. Which physical examination tests provide clinicians with the most value when examining the shoulder? Update of a systematic review with meta-analysis of individual tests. Br J Sports Med. 2012;46:964-78.

39. Jiandani MP, Mhatre B. Physical therapy diagnosis: how is it different? J Postgrad Med. 2018;64(2):69-72.

40. Kellam JF, Archibald D, Barber JW, Christian EP, D'Ascoli RJ, Haynes RJ, Hecht SS, Hurwitz SR, Kellam JF, McLaren AC, Peabody TD, Southworth SR, Strauss RW, Wadey VM. The core competencies for general orthopaedic surgeons. J Bone Joint Surg Am. 2017;99(2):175-81.

41. Kibler WB. Shoulder rehabilitation: principles and practice. Med Sci Sports Exerc. 1998;30:40-50.

42. Kuijpers T, van der Windt D, Boeke AJ, Twisk JW, Vergouwe Y, Bouter LM, van der Heijden GJ. Clinical prediction rules for the prognosis of shoulder pain in general practice. Pain. 2006;120:276-85

43. Lange T, Matthijs O, Jain NB, Schmitt J, Lützner J, Kopkow C. Reliability of specific physical examination tests for the diagnosis of shoulder pathologies: a systematic review and meta-analysis. Br J Sports Med. 2017; 51:511-8.

44. Lenza M, Buchbinder R, Takwoingi Y, Johnston RV, Hanchard NCA, Faloppa $F$. Magnetic resonance imaging, magnetic resonance arthrography and ultrasonography for assessing rotator cuff tears in people with shoulder pain for whom surgery is being considered. Cochrane Database Syst Rev. 2013(9):CD009020

45. Lewis J, McCreesh K, Roy J-S, Ginn K. Rotator cuff Tendinopathy: navigating the diagnosis-management conundrum. J Orthop Sports Phys Ther. 2015;45: 923-37.

46. Lewis J. The end of an era? J Orthop Sports Phys Ther. 2018;48(3):127-9.

47. Littlewood C, Bury J, O'Shea A, McCreesh K, O'Sullivan K. How should clinicians integrate the findings of the Lancet's 2018 placebo-controlled subacromial decompression trial into clinical practice? Br J Sports Med. 2018;52(14):883-4.

48. Littlewood C, Lowe A, Moore J. Rotator cuff disorders: a survey of current UK physiotherapy practice. Shoulder Elbow. 2012;4:64-71.

49. Littlewood C, Malliaras P, Bateman M, Stace R, May S, Walters S. The central nervous system- an additional consideration in 'rotator cuff tendinopathy' and a potential basis for understanding response to loaded therapeutic exercise. Man Ther. 2013a;18(6):468-72.

50. Littlewood C, May S, Walters S. Epidemiology of rotator cuff tendinopathy: a systematic review. Shoulder Elbow. 2013b;5:256-65.

51. Luime J, Koes B, Hendriksen I, Burdorf A, Verhagen A, Miedema H, Verhaar $J A$. Prevalence and incidence of shoulder pain in the general population; a systematic review. Scand J Rheumatol. 2004;33:73-81.

52. McFarland EG, Maffulli N, Del Buono A, Murrell GA, Garzon-Muvdi J, Petersen SA. Impingement is not impingement: the case for calling it "rotator cuff disease". Muscles, Ligaments Tendons J. 2013;3(3):196-200.

53. McGarvey C, Harb Z, Smith C, Houghton R, Corbett S, Ajuied A. Diagnosis of rotator cuff tears using 3-tesla MRI versus 3-tesla MRA: a systematic review and meta-analysis. Skelet Radiol. 2016;45:251-61.

54. Neer C. Anterior acromioplasty for the chronic impingement syndrome in the shoulder: a preliminary report. J Bone Joint Surg Am. 1972;54:41-50.

55. Nyberg A, Jonsson P, Sundelin G. Limited scientific evidence supports the use of conservative treatment interventions for pain and function in patients with subacromial impingement syndrome: randomized control trials. Phys Ther Rev. 2010;15(6):436-52.
56. Östör AJK, Richards CA, Prevost AT, Speed CA, Hazleman BL. Diagnosis and relation to general health of shoulder disorders presenting to primary care. Rheumatology. 2005;44:800-5.

57. Ottenheijm RP, Jansen MJ, Staal JB, van den Bruel A, Weijers RE, de Bie RA, Dinant G-J. Accuracy of diagnostic ultrasound in patients with suspected subacromial disorders: a systematic review and meta-analysis. Arch Phys Med Rehabil. 2010;91:1616-25.

58. Pieters L, Voogt L, Bury J, Littlewood C, Feijen S, Cavaggion C, Struyf F. Rotator CUFF disorders: a survey of current physiotherapy practice in Belgium and the Netherlands. Musculoskelet Sci Pract. 2019;43:45-51.

59. Pribicevic $M$, Pollard $H$, Bonello R. An epidemiologic survey of shoulder pain in chiropractic practice in Australia. J Manip Physiol Ther. 2009;32(2):107-17.

60. Ristori D, Miele S, Rossettini G, Monaldi E, Arceri D, Testa M. Towards an integrated clinical framework for patient with shoulder pain. Arch Physiother. 2018;8:7.

61. Rossettini G, Palese A, Geri T, Fiorio M, Colloca L, Testa M. Physical therapists' perspectives on using contextual factors in clinical practice: findings from an Italian national survey. PLoS One. 2018;13(11):e0208159.

62. Roy JS, Braen C, Leblond J, Desmeules F, Dionne CE, MacDermid JC, Bureau NJ, Frémont P. Diagnostic accuracy of ultrasonography, MRI and MR arthrography in the characterisation of rotator cuff disorders: a systematic review and meta-analysis. Br J Sports Med. 2015;49:1316-28.

63. Ryan M, Bisset L, Newsham-West R. Should we care about tendon structure? The disconnect between structure and symptoms in tendinopathy. J Orthop Sports Phys Ther. 2015;45(11):823-5.

64. Saltychev M, Äarimaa V, Virolainen P, Laimi K. Conservative treatment or surgery for shoulder impingement: systematic review and meta-analysis. Disabil Rehabil. 2015;37(1):1-8.

65. Saltychev M, Virolainen P, Laimi K. Conservative treatment or surgery for shoulder impingement: updated meta-analysis. Disabil Rehabil. 2020;42(11): 1634-5.

66. Steuri R, Sattelmayer M, Elsig S, Kolly C, Tal A, Taeymans J, Hilfiker P. Effectiveness of conservative interventions including exercise, manual therapy and medical management in adults with shoulder impingement: a systematic review and meta-analysis of RCTs. Br J Sports Med. 2017;51(18): 1340-7.

67. Struyf F, de Hertogh W, Gulinck J, Nijs J. Evidence-based treatment methods for the Management of Shoulder Impingement Syndrome among DutchSpeaking Physiotherapists: An online, web-based survey. J Manip Physiol Ther. 2012;35(9):720-6.

68. Tempelhof S, Rupp S, Seil R. Age-related prevalence of rotator cuff tears in asymptomatic shoulders. J Shoulder Elb Surg. 1999:8:296-9.

69. Tran G, Cowling P, Smith T, Bury J, Lucas A, Barr A, Kingsbury SR, Conaghan $P G$. What imaging-detected pathologies are associated with shoulder symptoms and their persistence? A systematic literature review. Arthritis Care Res (Hoboken). 2018;70(8):1169-84. https://doi.org/10.1002/acr.23554

70. Turgut E, Duzgun I, Baltaci G. Effects of scapular stabilization exercise training on scapular kinematics, disability, and pain in subacromial impingement: a randomized controlled trial. Arch Phys Med Rehabil. 2017; 98(10):1915-23.

71. von Elm E, Altman DG, Egger M, Pocock SJ, Gøtzsche PC, Vandenbroucke JP. STROBE initiative, strengthening the reporting of observational studies in epidemiology (STROBE) statement: guidelines for reporting observational studies. BMJ. 2007:335:806-8.

72. Walch G, Liotard JP, Boileau P, Noël E. Postero-superior glenoid impingement. Another impingement of the shoulder. J Radiol. 1993;74:47-50.

73. Zheng $X Q$, Li K, Wei YD, Tie HT, Yi XY, Huang W. Nonsteroidal antiinflammatory drugs versus corticosteroid for treatment of shoulder pain: a systematic review and meta-analysis. Arch Phys Med Rehabil. 2014;95(10): 1824-31.

\section{Publisher's Note}

Springer Nature remains neutral with regard to jurisdictional claims in published maps and institutional affiliations. 